\title{
The relationship between TQM and business performance: The mediating role of innovation performance and organizational learning culture: A pitch
}

\author{
Hafiz Ahmad Ashraf a,1 \\ ${ }^{a}$ Imperial College of Business Studies (ICBS), Pakistan
}

\begin{abstract}
This pitch research letter (PRL) is shaped by the pitch mold initiated by Faff $(2015,2019)$, for the proposed research project on the relationship between total quality management (TQM) and business performance: The mediating role of innovation performance and organizational learning culture (OLC) in developing countries. The beginning includes the antecedents enforcing my pitch motivations for doing pitch work. This PRL shows that pitch template is a modern style of researching as it starts from the proposal and has the power of dissertation defense. This PRL will shadow some of my research work and some personal reflections about the importance of the pitch template.
\end{abstract}

Keywords: Pitch Research Letter, TQM, Microfoundations of institutional theory

JEL codes: L1, L15

\section{Introduction}

A PRL is the set of parameters developed by Faff $(2015,2019)$ to cover a real-time problem in an academic research project. My interest in pitching research started when Professor Robert Faff introduced the tool during a webinar in a business course in the first semester of my $\mathrm{PhD}$ program. Since that time, I have considered

\footnotetext{
1 Corresponding author: Imperial College of Business Studies (ICBS), Bahria Town, Shahkam Chowk, Canal Bank Road Lahore - Pakistan, Pakistan; tel. +92 0553835741 ; email address: ucpahmad@gmail.com
} 
the template an essential inclusion in my research. Applying the pitching research assisted me to understand literature, structure, and design the research, and to provide a clearer picture of the approach to follow when writing. Although many researchers understand and use literature search appropriately, others have a limited understanding of the process. Such individuals become overwhelmed quickly as underscored by their off-topic ideas. Such challenges can be eliminated by using the template, which makes it easier to navigate literature and determine the essential ones. The pitch will make it easier for me to do research systematically to highlight the issues that should be addressed. The pitch template is a standard structure in writing the introduction. By the time a person is done with the template, the introduction is complete. I am sharing this pitch research to allow researchers to take advantage of the tool.

Further, this PRL is divided into the following parts. In part 2, I have presented a brief review of my pitch. Some personal reflections of doing PRL are shown in part 3 , and Part 4 concludes the whole exercise of PRL

\section{A brief reflection on the pitch}

The completed PRL arranged in Table 1, the adoptive face of pitch template of Faff (2019), which is so simple and easy for all researchers. Table 1 presents the completed pitch on the topic "The relationship between EFQM enablers and business performance: The mediating role of innovation performance and organizational learning culture" (item A). The primary research question (item B) is 'Do micro-foundations of institutional theory explain the development of OLC through EFQM enablers?' The key papers (KPs) (item C) relevant to the primary research? are by Cardinale (2019), Kafetzopoulos et al. (2019) and Powell \& Rerup (2017). These KPs are based on the three selection criteria advised by Faff (2017): 1) recently published, 2) in top-ranked journals 3) by the experts in the relevant field. The last part (item D) 'answers' to all the queries asked by Faff (2017) template: Idea, Tools, Data, So What, What is New, Contribution, and Other Considerations.

\section{Brief personal reflections}

Work can be efficiently completed if particular follow-ups follow it, but it is difficult as one has to make one's outlines to complete the work (Ali, 2016). I had to face this as I completed my $\mathrm{PhD}$ thesis work in a year. However, my views are similar to those of Faff (2019), who says that work is difficult before you take the step to start it. 
The relationship between TQM and business performance: The mediating role of innovation performance and organizational learning culture: A pitch

Table 1. Completed 2-page pitch template on relationship between TQM and business performance

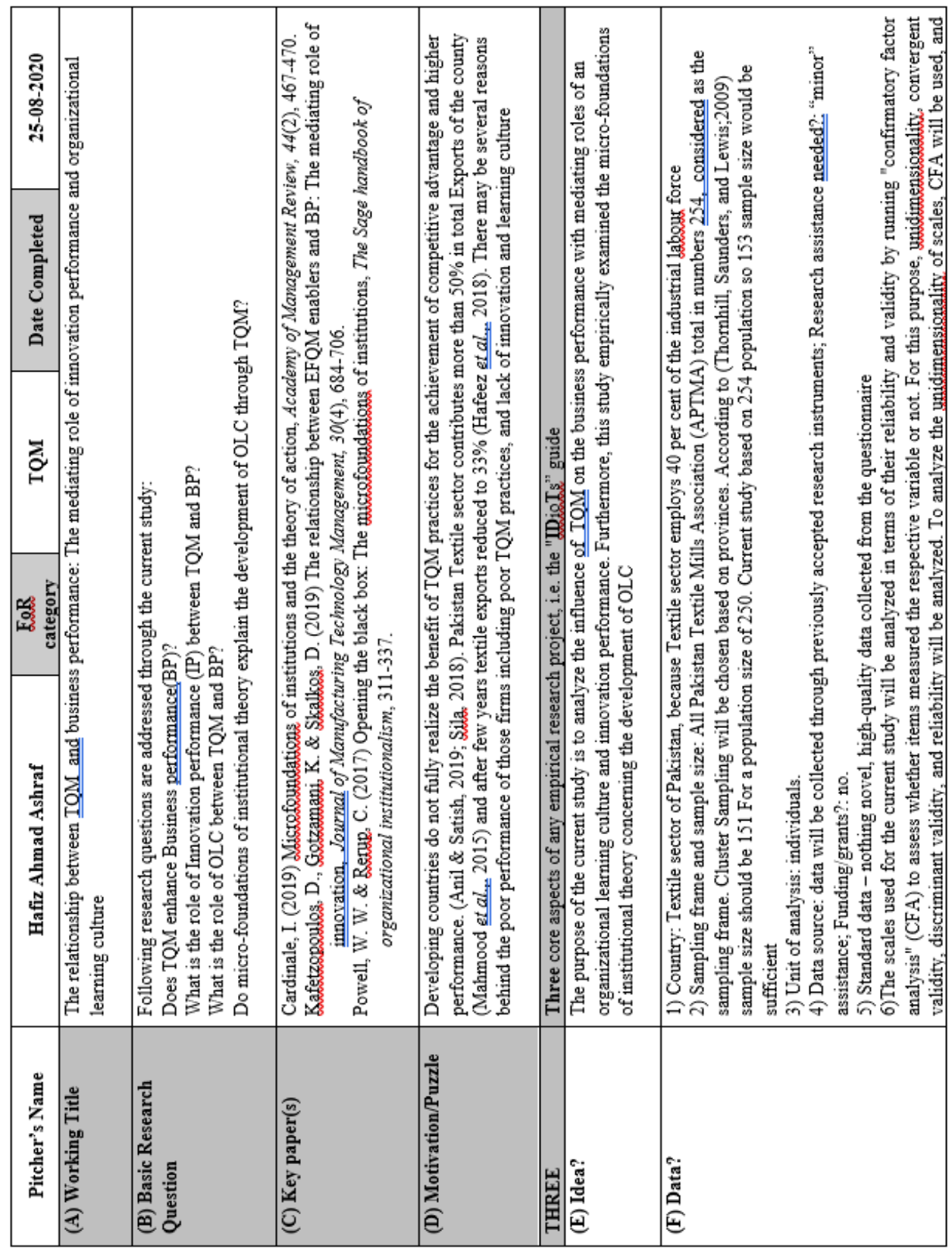

Vol. 20, No. 1 


\begin{tabular}{|c|c|c|c|c|c|c|}
\hline 言 & 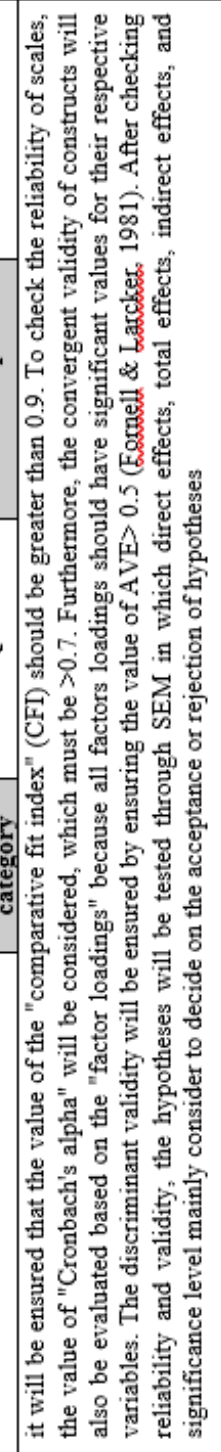 & 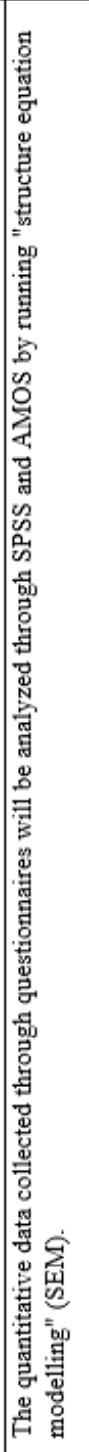 & 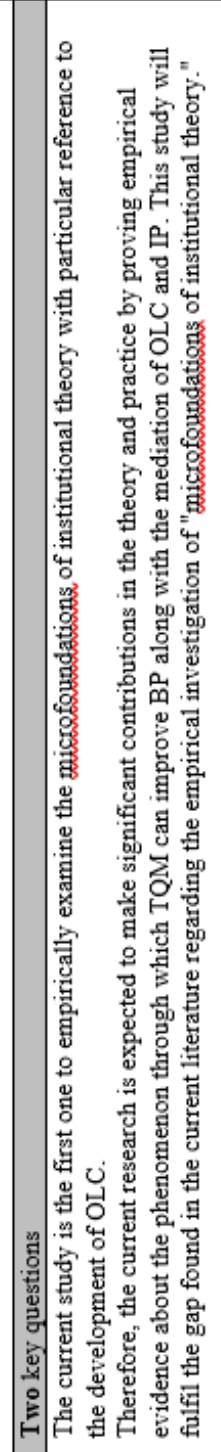 & 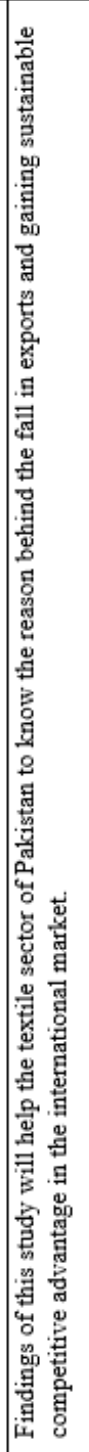 & 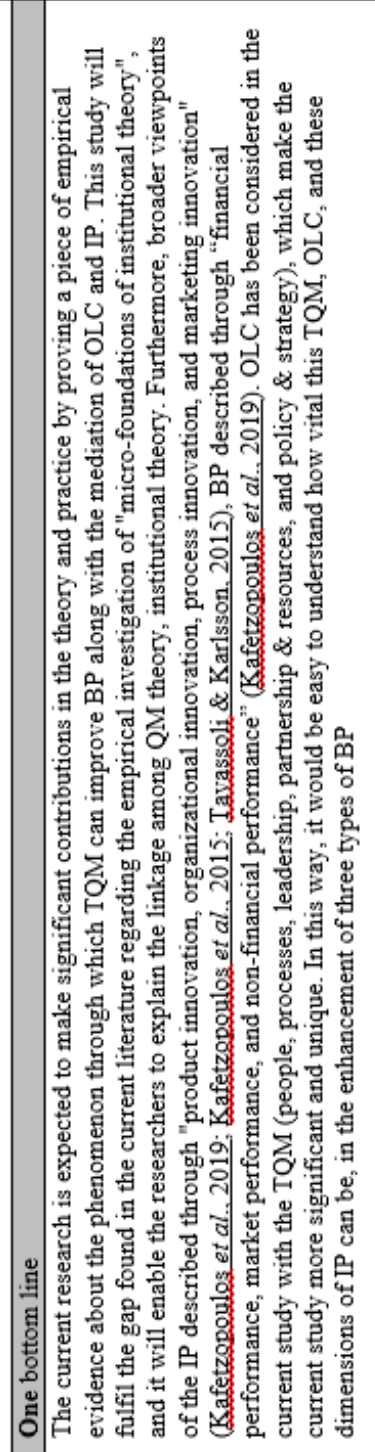 & 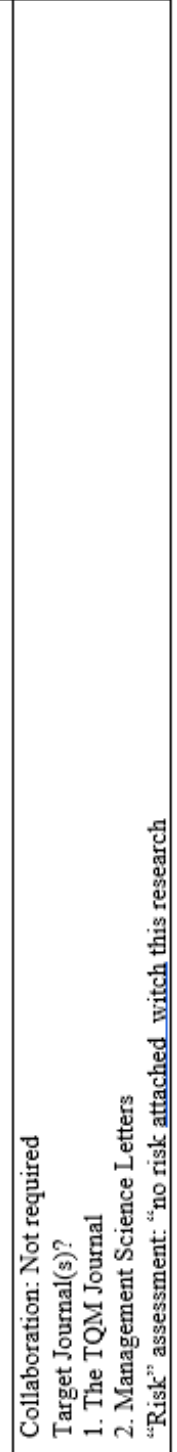 \\
\hline 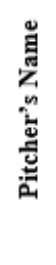 & & & | & & 焉 & 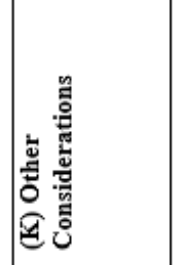 \\
\hline
\end{tabular}


The relationship between TQM and business performance: The mediating role of innovation performance and organizational learning culture: A pitch

\subsection{Hearing about pitch templates}

I heard about pitch templates when I attended the webinar of Robert Faff. I was about to complete my PhD course work and to start my preparations for my final $\mathrm{PhD}$ proposal. I developed a first pitching draft of my research idea and presented it in a Pakistan pitching research competition (APPRC 2017-2018) my idea was among the top 20 pitches, and I was honored to receive my appreciation letter and prize from Robert Faff. Finally my research supervisor Prof. Ishtiaq motivated me to follow Faff (2019), Ashraf and Manzoor (2017) and Iqbal and Ashraf (2017), which was my 2 nd step in the pitch valley. I faced several problems in doing my research work, but Faff's (2019) guidelines acted as a motivator to me in that one cannot be clear about the research unless one has a firm grip on the theory and literature of the desired work.

\subsection{Venn Diagram}

A diagram is a hacking code used to simplify challenging ideas into concise and easy way to the reader. Often a diagram can serve as a sort of communication where words are limit, bridging the difference between vocal and non-vocal language and converting the multilingual into the unilingual. While visiting Japan, I saw Japanese people in the silent mood and following different diagrams and charts at stations, factories, auctions, malls, and public places. This led me to see Japan as 'the valley of diagrams' as I did not initially understand the Japanese language and use diagram to communicate with people. My Japanese teacher always carried a diary and a pen, and he taught me Japanese by drawing different characters, according to him 'the base of Japanese kanji is just a picture'. When I started pitching exercise, I recognized that the Venn diagram theory by Faff (2016) and Japanese character based writing system were very similar. So due to my practical exposure I was able to quickly grasp the essence and usage of charts and graphs. My understanding of the further cleared when in Disney Land I saw people associating the theme park with Mickey Mouse due to his unique and ionic character. Keeping these ideas in view, I drew a Venn diagram of my research idea shown in Figure 1.

\subsection{Process usage of "Pitch Research letter"}

According to my exposure, PRL is not just an essential, meditational, or final step as it covers and can assist the whole research process. As PRL is not merely a template the research idea, it also guides the nascent researcher in the selection and refining of their research idea (Ali, 2016). Based on my practical experience, I am providing the research work in the field of pitching, namely PRL (Pitch Research Letter). 


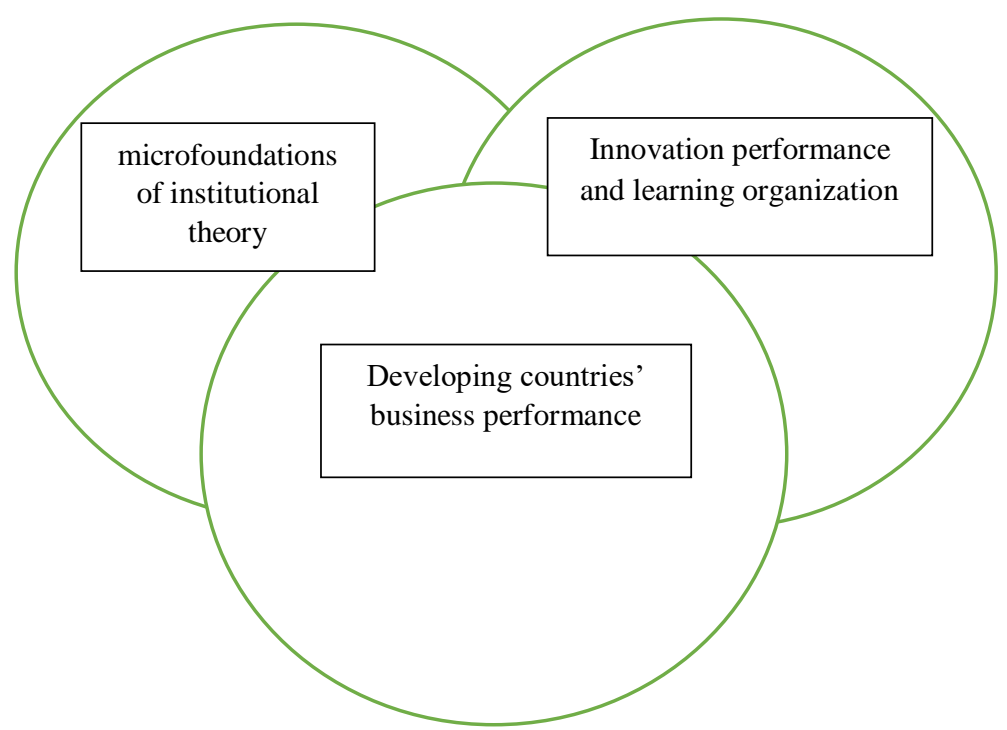

Figure 1. Mickey Mouse Venn Diagram

\section{Conclusion}

This PLR exercise has given me the chance to cover the research ideas in the form of pitch, on the topic "The relationship between TQM and business performance: The mediating role of innovation performance and organizational learning culture". This pitching exercise serves as an outline for me in the whole research process as PRL provides me with a system from start to end. So I recommend all researchers to use this opportunity provided by Faff (2019).

\section{References}

Ashraf, H. A. \& Manzoor, N. (2017) "An examination of customer loyalty and customer participation in the service recovery process in the Pakistani hotel industry: A pitch", Accounting and Management Information Systems, vol. 16, no. 1: 199-205

Ali, S. (2016) "Corporate governance and stock liquidity in Australia: A pitch", Accounting and Management Information Systems, vol. 15, no. 3: 624-631

Anil, AP \& KP, S. (2019) "TQM practices and its performance affects - an integrated model", International Journal of Quality \& Reliability Management, vol. 36, no. 8: 1318-1344 
The relationship between TQM and business performance: The mediating role of innovation performance and organizational learning culture: A pitch

Cardinale, I. (2019) "Microfoundations of institutions and the theory of action", Academy of Management Review, vol. 44, no. 2: 467-470.

Faff, RW (2015) "A simple template for pitching research", Accounting \& Finance, vol. 55, no. 2: 311-336

Faff, RW (2019) Pitching research ${ }^{\circledR}$, Available at SSRN 2462059.

Hafeez, M.H., Basheer, MF, Rafique, M. \& Siddiqui, S.H. (2018) "Exploring the Links between TQM Practices, Business Innovativeness and Firm Performance: An Emerging Market Perspective", Pakistan Journal of Social Sciences (PJSS), vol. 38, no. 2: 485-500

Iqbal, H. \& Ashraf, H.A. (2017) "Impact of behavioural factors towards the adoption of mobile learning among higher education students in public and private universities: A pitch", Accounting and Management Information Systems, vol. 16, no. 3: 406-412

Kafetzopoulos, D., Gotzamani, K. \& Gkana, V. (2015) "Relationship between quality management, innovation and competitiveness. Evidence from Greek companies", Journal of Manufacturing Technology Management, vol. 26, no. 8: 1177-1200

Kafetzopoulos, D., Gotzamani, K., \& Skalkos, D. (2019) "The relationship between EFQM enablers and business performance: The mediating role of innovation", Journal of Manufacturing Technology Management, vol. 30, no. 4: 684-706.

Mahmood, S., \& Ahmed, A. (2015) "The role of organizational learning in understanding the relationship between total quality management and organizational performance", Pakistan Journal of Commerce and Social Sciences, vol. 9, no.1: 282-302.

Powell, W.W. \& Rerup, C. (2017) "Opening the black box: The microfoundations of institutions", The Sage handbook of organizational institutionalism, 2 : 311-337

Saunders, M., Lewis, P. \& Thornhill, A. (2009) Research methods for business students, Pearson education, Harlow, England

Sila, I. (2018) "Linking quality with social and financial performance: A contextual, ethics-based approach", Production and Operations Management, vol. 27, no. 6: 1102-1123

Tavassoli, S. \& Karlsson, C. (2015) "Persistence of various types of innovation analyzed and explained", Research Policy, vol. 44, no. 10: 1887-1901 